\title{
The Prediction Error of the Chain Ladder Method (With Application to Real Data)
}

\author{
Afaf Antar Zohry ${ }^{1} \&$ Mostafa Abdelghany Ahmed ${ }^{1}$ \\ ${ }^{1}$ Department of Mathematics and Insurance, Faculty of Commerce, Cairo University, Egypt \\ Correspondence: Afaf Antar, Department of Mathematics and Insurance, Faculty of Commerce, Cairo University, \\ Giza, 12631, Egypt.
}

Received: October 2, 2020

Accepted: October 29, 2020

Online Published: November 5, 2020

doi:10.5539/ijef.v12n12p14

URL: https://doi.org/10.5539/ijef.v12n12p14

\begin{abstract}
The chain ladder method is the most widely used method of estimating claims reserves due to its simplicity and ease of application. It is very important to know the accuracy of the resulting estimates. Murphy presented a recursive model to estimate the standard error of claims reserves estimates, in line with the solvency ii requirements as a new regulatory framework adjusted according to risk, which requires the necessity to estimate the error and uncertainty of the claims reserving estimates. In Murphy's model, the mean square error (MSE) is analyzed into its components: variance and bias. In this paper, the recursive model of Murphy was used to estimate the prediction error in claims reserves estimates of General Accident \& Miscellaneous Insurance in one of the Egyptian insurance companies.
\end{abstract}

Keywords: chain ladder, Mack, Murphy model, mean square error, parameter risk, process risk, recursive calculation.

\section{Introduction}

The aim of insurance supervision is to protect the legitimate interests of policyholders and other beneficiaries, in the context of encouraging an honest and competitive financial market. To achieve this goal, the supervisor needs a large degree of understanding and familiarity with the risks associated with insurance and the management of the insurance business (Majmudar, 2011).

Because accidents of claims that include the number and values of claims are usually random, it is important to estimate claims reserves accurately and carefully, as underestimation may lead to the company's need for more reserves, which in turn may lead to an inflation of profits and reduction in the reliability of the company in addition to problems that may occur in the financial solvency, and in the worst - case scenario may lead to insolvency of the insurance company. Furthermore, overestimation may lead to allocating and reserving excess and ineffective capital and charging the company a higher total capital cost rather than using it for its proper purposes (Pinheiro et al., 2003; Mann, 2011).

Estimating claims reserves is considered one of the basic actuarial tasks in the insurance industry, because it provides us with certainty about whether the insurance company has or hasn't been sufficient solvency and liquidity, and also gives us indications about the company's ability/inability to pay off debts at any time in the future. Due to the importance of these estimates and the variance in unpaid liabilities, several methods and models have been developed to arrive at correct estimates (Tee et al., 2017).

Claims Reserves can be defined as an amount of money set aside to meet future payments associated with claims incurred but not yet settled at the time of a given date (Hayne, 2017).

Usually, reserves can be classified into two parts depending on the stage of settlement of the claim that has reached:

- Claims reserves required for claims reported but not yet closed. These reserves are known as reported but not settled reserves.

- Claims reserves required in relation to claims that have been incurred but not reported, referred to as Incurred but Not Reported (IBNR) (Ochola, 2009).

Total unpaid claims represent the unknown random variable, while cumulative incurred claims represent the 
known constant value. The sum of both the estimated total expected unpaid claims and the cumulative incurred claims is equal to the ultimate claims that are vital to the company's balance sheet and management decision. One of the most important aspects of an insurance company is estimating the ultimate claims. (Mann, 2011; Ochola, 2009).

\section{Methods and Models Used in Estimating Claims Reserves}

The methods and models used in estimating claims reserves can be divided into two types: Deterministic methods and stochastic models (Mann, 2011).

\subsection{Deterministic Methods - Actuarial Best Estimate (ABE)}

Deterministic methods are also known as traditional methods, basic methods, actuarial methods, non-stochastic methods. These methods are characterized by the following:

- Its use of claims data from the past experience period.

- Its estimation of claims reserves using well-known common sense methods such as using simple averages and algebraic formulas.

- Establishing assumptions about the expected value of future claims.

- The ability to make quick adjustments to the data used therein, such as the change that may occur in the claims settlement rate.

- Establishing a one-point estimate (one value) of future claims that will be paid (Straub \& Grubbs, 1998).

The point estimate of claims reserves mean the average or central value of claims reserves. The increased demand for more insight into the extent of variability in claims and their volatility has led to the development of stochastic models for estimating this reserve (Ogutu, 2011).

Among the advantages of deterministic methods is that they produce or give us one answer, i.e. the best actuarial estimate which is easy to understand and through which we can easily communicate with management (IOA \& FIAA, 2016).

However, it may be better to consider stochastic models rather than deterministic methods for the following reasons (Charles \& Westphal, 2006):

- Deterministic methods only give a point estimate of claims liabilities.

- The Best Estimate is usually chosen based on the actuary's personal judgment.

- Deterministic methods do not assess the expected difference between estimates of expected claims and actual future payments (claims). Unlike stochastic models, it is concerned with the extent of change in unpaid claims.

- A major weakness of the deterministic methods is that they provide little understanding of the level of uncertainty associated with the actuarial best estimate. Therefore, a stochastic model is needed.

\subsection{Stochastic Models}

Based on past data, an estimate of expected unpaid claims is obtained. However, in the event of poor data quality, or even the occasional lack of data, unexpectedly large claims being paid, or changes in the inflation regime and even legal or political factors, the uncertainty of the actuarial best estimate can be very high (Björkwall, 2011).

Obviously, there is a risk that the claims reserve will not be sufficient for ultimately pay all claims, resulting in a negative outcome to the claims development triangle. In order to monitor and manage this risk, it is important that the actuarial best estimate is supplemented with some measures of variance that the insurance company can follow (Björkwall, 2011).

Hence, it can be said that stochastic claims reserving models aim to provide measures of location (Best Estimates) and measures of precision (measures of variability), by treating the reserves estimation process as data analysis and construct a model for estimating reserves according to a statistical framework. Stochastic models also permit the use of computer power and statistical methodology (England \& Verrall, 2002).

The actuary must be aware of a very important fact, which is that the use of stochastic models to estimate claims reserves do not provide solutions when deterministic methods fail. Rather, it determines the uncertainty in deterministic methods of estimating reserves. Also, if a substantial level of the personal judgment of the actuary is required, it is unlikely that stochastic models will be appropriate in this situation (Wüthrich \& Merz, 2008; England \& Verrall, 2002). 


\subsection{Sources of Uncertainty in Prediction}

They are also known as the sources or elements of risk, sources of error, or sources of variance in an estimate.

Claims reserves are estimates of total future payments that are required to settle claims for accidents that have actually occurred (Panning, 2006).

Actual future payments may deviate or differ from the expected estimated values for several reasons, each of which reflects a different risk, or in other words, sources of error in claims reserves estimates come from three types of risks: process risk, parameter risk, and model risk. The actuarial analysis of risk and uncertainty is based on these three categories (Gutterman, 2017; Panning, 2006).

\subsubsection{Process Risk}

The Process risk is also known as Process Error, Process Uncertainty, or Process Variance. It is sometimes referred to a statistical risk or statistical error or stochastic error. It is also known as the Process Standard Error (Ashe, 1986; Gutterman, 2017).

It can be defined as the risk of unavoidable random fluctuations occurring in any random process, and this risk occurs even if the actuary chooses a completely accurate model, and the distribution parameters are accurately estimated in this model (Gutterman, 2017).

Dealing with this source of error (process risk) is rather easy, as it is the most traceable and therefore, the most common error when calculating such things (Ashe, 1986). For example, the process of claims payments settlement involves some degree of uncertainty. The actual paid value is a complex result of many factors, such as uncertain outcomes, cost of diagnosis and treatment, court procedures and settlement negotiations. None of these factors can be easily predicted (Panning, 2006).

\subsubsection{Parameter Risk}

It is also known as Parameter Error, Parameter Uncertainty, Parameter Variance, Estimation Error, Estimation Variance, Estimation Uncertainty, or Parameter Standard Error.

Parameter risk arises because the information (data) related to the basic probability distribution is necessarily incomplete, or because the resulting distribution is inappropriate, or incorrect (Gutterman, 2017).

Deterministic methods necessarily use past experiences to predict future patterns. However, sometimes that past experience can be misleading, mainly due to the short time period covered by the paid claims table, and hence the parameter estimates are derived from a relatively small number of observed data (Panning, 2006).

As a result, it is very possible that past data reflect the experience of unusually appropriate or inappropriate claims, and this in turn affects the model parameters which should be estimated accurately (Panning, 2006).

\subsubsection{Model Risk}

Model risk is also known as model error, model uncertainty, model variance, or specification error.

Model risk arises when the reality model used for estimation is incorrectly identified or chosen. The reason for the error is usually either because the important factors in the process being modeled (claims process) is not known, or because of the available data are limited. The model risk is very difficult to estimate (Ashe, 1986).

\section{Measures of Claims Reserves Uncertainty}

With the increase in computing power and the development of statistical theories, the amount of work being done on the statistical nature of the errors has to be involved in the estimation (Ashe, 1986).

The natural step after the first moment of the value of claims reserves (i.e. the mean) is the second moment (i.e. the variance), which has received the most attention. The most widely used measure of prediction error is the mean squared error of prediction (MSEP) which is also used as an accuracy measure of reserve estimates in most literature (Ashe, 1986).

The mean squared error of prediction is known as prediction error for short, it is also called prediction risk, prediction variance, and prediction uncertainty. MSEP can be divided into two components (IOA \& FIAA, 2016):

- Parameter risk;

- Process risk.

The MSEP computation certainly provides important information about the performance of the reserve estimates (Tee et al., 2017). 
The sum of the process risk and the parameter risk is called the measure of variance, the extent of change in prediction, or the standard error, which is calculated by taking the square root of the mean squared error of prediction (RMSEP) where:

Prediction variance $=$ process variance + estimation variance

When trying to estimate the Prediction error of future payments and reserve estimates using stochastic models, the problem is reduced to estimating two components: process variance and parameter variance (Ogutu, 2011).

Coefficient of Variation ( $\mathrm{CoV}$ ) is also used frequently to express the uncertainty in a reserve. It can be defined as the standard deviation or standard error measure divided by the central estimate. Where in the case of reserves, the numerator is RMSEP, and the denominator is either ultimate claims reserves or outstanding claims reserves (IOA \& FIAA, 2016).

\section{Murphy's Model for Estimating Risk in Claims Reserves}

Several methods and models for estimating claims reserves have evolved as deterministic. However, predicting outstanding claims is not sufficient, but it is also necessary to estimate the uncertainty in these estimates. To determine the amount and uncertainty of claims reserves, the actuary has to model the stochastic nature of the claims process (Saluz, 2014).

Besides, in recent years, especially under the new solvency regulations, there has been great interest in the adverse development of claims reserves,

And the estimation of potential losses that may occur in the future in the best estimate of these reserves (Wüthrich \& Merz, 2008). Such problems require stochastic models to:

- Justify and endorse the methods of estimating claims reserves;

- Determine the uncertainty in these methods.

Thomas Mack has derived formulas for reserve risk according to the chain ladder method, where development factors are based on a weighted average for all years. He also provided a formula for total risk (standard error) (Mack, 1993).

The reserve risk is measured according to the Mack method by the mean square error, whereas according to the Murphy method it is measured by the total variance (Murphy, 2007). As for the mean square error, it can be analyzed into three components:

- Process risk;

- Parameter risk;

- Bias.

\subsection{Murphy's Model Assumptions}

Murphy's model is based on the same assumptions as Mack's model (Mack, 1993; Murphy, 2007). The Mack's model relies on three main assumptions, and it appears from these assumptions that they depend on the deterministic chain ladder method, and these assumptions are as follows:

- The Expectation of the claims in the accident year $i$ and the development year $k+1$ with knowledge of claims: $C_{i, 1} \ldots \ldots \ldots, C_{i, k}$ is as follows:

$$
E\left(C_{i, k+1} \mid C_{i, 1}, \ldots \ldots C_{i, k}\right)=C_{i, k} \cdot f_{k}, 1 \leq i \leq I, 1 \leq k \leq I-1
$$

Where:

$C_{i, k}$ The cumulative total paid claims amount of accident year $i$ and development year $k$, and we have the observed value of the paid claims in the case of: $i+k \leq I+1$

$I$ The last observed accident year, the ultimate development year

$f_{k}$ Cumulative paid claims development factors, which are estimated by the estimator $\hat{f}_{k}$

- The independence of $C_{i, k}$ for the different accident years, because the steps of calculating the chain ladder method do not take into account any dependencies between the different accident years, and this means that: $\left\{C_{i, 1}, \ldots \ldots, C_{i, I}\right\},\left\{C_{s, 1}, \ldots \ldots, C_{s, I}\right\} i \neq s$ are independent. This previous assumption must be considered as another implicit assumption of the chain ladder method.

- Claims Variance Assumption:

It is known that $\hat{f}_{k}$ is the weighted average of the paid claims in accident year $i$ and development year $k$ of the 
individual development factors $C_{i, k+1} / C_{i, k}, 1 \leq i \leq I-k$, it can be concluded that: $\operatorname{Var}\left(\hat{f}_{k}\right)=\operatorname{Var}\left(C_{i, k+1}\right) / C_{i, k} \mid C_{i, 1}, \ldots, C_{i, k}$. It must be inversely proportional to, $C_{i, k}$, i.e.:

$$
\begin{gathered}
\frac{\operatorname{Var}\left(C_{i, k+1} \mid \mathrm{C}_{\mathrm{i}, 1}, \ldots, \mathrm{C}_{\mathrm{i}, \mathrm{k}}\right)}{C_{i, k}}=\sigma_{\mathrm{k}}^{2} \\
\operatorname{Var}\left(C_{i, k+1} \mid C_{i, 1}, \ldots, C_{i, k}\right)=C_{i, k} \sigma_{k}{ }_{k}, \quad 1 \leq i \leq I, 1 \leq k \leq I-1
\end{gathered}
$$

Where:

$\sigma_{\mathrm{k}}^{2}$ Unknown claims variance parameters, which are estimated by the estimator $\hat{\sigma}_{k}^{2}$ (variance estimator)

On the other hand, it is known that the chain ladder estimates of the most-recent accident years are very sensitive to changes in the observed data (values of paid claims according to the accident year and the development year). Hence, it will be very important to know the standard error for the estimates of the chain ladder, to take it as a measure of the uncertainty contained in the data, and to know whether the difference between the results of the chain ladder method, and any other method is significant or not.

\subsection{The Theoretical Framework of Murphy's Model}

Mack has derived the closed-form formula to estimate the mean square error for the estimated ultimate claims reserves using the chain ladder method and from which he arrived at an estimate of the total standard error of claims reserves (Mack, 1993). According to the Murphy model, there is a formula for estimating the process risk and another formula for estimating the parameter risk (Murphy, 2007).

\subsubsection{Estimating the Development Factors $f_{k}$}

The development factors $f_{k}$ are estimated using the estimator $\hat{\mathrm{f}}_{k}$ (Estimated development factors) Using the weighted averages of all the cumulative paid claims years as follows:

$$
\hat{\mathrm{f}}_{k}=\frac{\sum_{j=1}^{I-k} C_{j, k+1}}{\sum_{j=1}^{I-k} C_{j, k}}
$$

\subsubsection{Estimating the Future Claims Amount}

The future claims amounts for future years $(k>I+1-i)$ are estimated as follows:

4.2.3 Estimating the Outstanding Claims Reserve

$$
\hat{C}_{i, k+1}=C_{i, k} \cdot \hat{\mathrm{f}}_{k}
$$

The outstanding claims reserve is estimated as follows:

\subsubsection{Analysis of the Mean Square Error}

$$
\hat{R}_{i}=\hat{C}_{i, I}-C_{i, I+1-i}
$$

The mean square error for the accident year $i$ and the ultimate development year $I$ for the estimator $\hat{C}$, can be defined as the expected squared deviation of $\hat{C}$ (which is a random variable) from the value of the random variable $C$ which is estimated by:

$$
\operatorname{mse}(\hat{C})=E(\hat{C}-C)^{2}
$$

The mean square error can be decomposed into Variance and Bias as follows:

$$
m s e(\hat{C})=\operatorname{Var}(C)+\operatorname{Var}(\hat{C})+\operatorname{Bias}^{2}(\hat{C})
$$

Hence the mean square error consists of the sum of the process risk, parameter risk, and the square of the bias of $\hat{C}$.

According to the Murphy's model, both process risk and parameter risk will be estimated separately, the process risk for future claims using the same Mack notations will be calculated as follows:

\subsubsection{Process Risk Estimation}

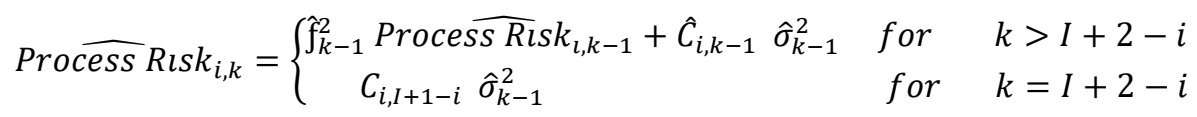

From the previous equation, it becomes clear that we need an estimator for $\hat{\sigma}_{k}^{2}$ which is calculated with the same Mack formula as follows:

Which is an unbiased estimator for $\sigma^{2}$.

$$
\hat{\sigma}_{k}^{2}=\frac{1}{I-k-1} \sum_{i=1}^{I-k} C_{i, k}\left(\frac{C_{i, k+1}}{C_{i, k}}-\hat{\mathrm{f}}_{k}\right)^{2}, 1 \leq k \leq I-2
$$

Since the previous equation is used in the case of: $1 \leq k \leq I-2$, then the estimator for $\sigma_{I-1}^{2}$ is still required. This is calculated with the same Mack formula as follows: 


$$
\sigma_{I-1}^{2}=\min \left(\hat{\sigma}_{I-2}^{4} / \hat{\sigma}_{I-3}^{2}\right), \min \left(\hat{\sigma}_{I-3}^{2}, \hat{\sigma}_{I-2}^{2}\right)
$$

The recursive method of Murphy is evident through equation (8) for calculating the process risk, in which the process risk is calculated for each accident year $i$ and the development year $k$ through the data of the year immediately preceding it, i.e. by using the accident year $i$ and the previous development year $k-1$, the calculation is done at the row level, meaning that the accident year $i$ is fixed and reliant on the immediately preceding development year for each development year (Murphy, 2007).

\subsubsection{Parameter Risk Estimation}

The closed-form estimator (equation) of parameter risk according to Mack's model can be seen as follows:

$$
\text { Parameter } R \imath s k_{i, k}=\hat{C}_{i, k}^{2} \sum_{j=I+1-i}^{k-1} \frac{\widehat{\sigma}_{j}^{2}}{\hat{f}_{j}^{2}} \frac{1}{\sum_{r=1}^{I-j} C_{r, j}}
$$

According to the recursive Murphy model, equation (11) can be reformulated in a recursive manner by estimating the parameter risk for the development year $k$ depending on the development year immediately preceding it, which is the development year $k-1$. By substituting each $k$ with $k-1$ and each $\mathrm{j}$ with $k-1$ in equation (11), and also each $\hat{\mathrm{C}}_{\mathrm{i}, \mathrm{k}}^{2}$ with $\hat{\mathrm{f}}_{\mathrm{k}-1}^{2} \hat{\mathrm{C}}_{\mathrm{i}, \mathrm{k}-1}^{2}$ (where; $\widehat{\mathrm{C}}_{\mathrm{i}, \mathrm{k}}^{2}$ is a product, $\hat{\mathrm{f}}_{\mathrm{k}-1}^{2} \widehat{\mathrm{C}}_{\mathrm{i}, \mathrm{k}-1}^{2}$ ), the parameter risk estimator according to Murphy can be calculated as follows (Murphy, 2007):

$$
\begin{aligned}
& \text { Parameter } R_{\imath} s k_{i, k}= \\
& \hat{\mathrm{f}}_{k-1}^{2} \hat{C}_{i, k-1}^{2}\left[\sum_{j=I+1-i}^{k-2} \frac{\widehat{\sigma}_{j}^{2}}{\hat{\mathrm{f}}_{j}^{2}} \frac{1}{\sum_{r=1}^{I-j} C_{r, j}}+\frac{\widehat{\sigma}_{k-1}^{2}}{\hat{\mathrm{f}}_{k-1}^{2}} \frac{1}{\sum_{r=1}^{I-k-1} C_{r, k-1}}\right] \\
& =\hat{\mathrm{f}}_{k-1}^{2} \hat{C}_{i, k-1}^{2} \sum_{j=I+1-i}^{k-2} \frac{\widehat{\sigma}_{j}^{2}}{\hat{\mathrm{f}}_{j}^{2}} \frac{1}{\sum_{r=1}^{I-j} C_{r, j}}+\hat{C}_{i, k-1}^{2} \frac{\widehat{\sigma}_{k-1}^{2}}{\sum_{r=1}^{I-k-1} C_{r, k-1}} \\
& =\hat{\mathrm{f}}_{k-1}^{2} \text { Parameter } R \iota s k_{i, k-1}+\hat{C}_{i, k-1}^{2} \widehat{\operatorname{Var}}\left(\hat{\mathrm{f}}_{k-1}\right)
\end{aligned}
$$

Hence the Murphy estimator of the parameter risk according to the recursive method using the same Mack notations is as follows:

$$
\text { Parameter Rlsk } k_{i, k}=\left\{\begin{array}{cc}
\hat{\mathfrak{f}}_{k-1}^{2} \text { Parameter } & \text { Rlsk }_{i, k-1+1} \hat{C}_{i, k-1}^{2} \widehat{\widehat{\operatorname{Var}}\left(\hat{\mathrm{f}}_{k-1}\right)+} \\
\widehat{\operatorname{Var}}\left(\hat{\mathrm{f}}_{k-1}\right) \text { Parameter Rlsk } k_{i, k-1} & \text { for } k>I+2-i \\
C_{i, I+1-i}^{2} \widehat{\operatorname{Var}}\left(\hat{\mathrm{f}}_{k-1}\right) & \text { for } k=I+2-i
\end{array}\right.
$$

Where:

$\widehat{\operatorname{Var}}\left(\hat{\mathrm{f}}_{k-1}\right)$ Represents the variance of the estimated development factors, which is also denoted by $\widehat{\sigma}_{\mathrm{f}_{\mathrm{k}-1}}^{2}$ and estimated through the following equation:

$$
\widehat{\operatorname{Var}}\left(\hat{\mathrm{f}}_{k-1}\right)=\hat{\sigma}_{\mathrm{f}_{k}-1}^{2}=\frac{\widehat{\sigma}_{k-1}^{2}}{\sum_{r=1}^{I-1-1} C_{r, k-1}}
$$

Hence, $\widehat{\operatorname{Var}}\left(\hat{\mathrm{f}}_{k}\right)$ which is also denoted by $\widehat{\sigma}_{f_{\mathrm{k}}}^{2}$, is calculated by the following equation:

$$
\widehat{\operatorname{Var}}\left(\hat{\mathrm{f}}_{k}\right)=\hat{\sigma}_{f_{k}}^{2}=\frac{\hat{\sigma}_{k}^{2}}{\sum_{r=1}^{I-k} C_{r, k}}
$$

The recursive method of Murphy is evident through equation (15) for estimating the parameter risk, where this risk is calculated for each accident year $i$ and development year $k$ through the data of the year immediately preceding it, that is, by using the accident year $i$ and the development year immediately preceding it $k-1$ by calculation method at the row level, that is, by fixing the accident year $i$ and relying on the immediately preceding development year for each development year (Murphy, 2007).

\section{Application to Real Data}

In our numerical example, we use a real data from one of the Egyptian insurance companies for General Accident \& Miscellaneous Insurance line for the period from 2009 (i=1) to 2018 ( $\mathrm{i}=10$ ). These data represent the cumulative paid claims according to the accident year $i$ and the development year $k$, denoted by $C_{i k}$. The year 2018 means the financial year ending on 30/06/2018. The authors chose that company to be the subject of study, because it is considered one of the largest insurance companies in the Egyptian insurance market, and can establish detailed claims and risk exposure data required by the actuary to estimate unpaid claims from their management information systems. Hence the following table represents the cumulative paid claims: 
Table 1. The Cumulative Paid Claims (in EGP 1000) of one of the Egyptian insurance companies

\begin{tabular}{|c|c|c|c|c|c|c|c|c|c|c|}
\hline$i$ & $C_{i, 1}$ & $C_{i, 2}$ & $C_{i, 3}$ & $C_{i, 4}$ & $C_{i, 5}$ & $C_{i, 6}$ & $C_{i, 7}$ & $C_{i, 8}$ & $C_{i, 9}$ & $C_{i, 10}$ \\
\hline 1 & 3260 & 24677 & 36412 & 40566 & 40582 & 40364 & 43536 & 43597 & 43808 & 44331 \\
\hline 2 & 10096 & 32158 & 40485 & 42053 & 42582 & 42702 & 44880 & 45998 & 46133 & \\
\hline 3 & 6635 & 27416 & 38242 & 41877 & 43138 & 42998 & 44229 & 44287 & & \\
\hline 4 & 5359 & 26877 & 39252 & 42101 & 43014 & 48127 & 48409 & & & \\
\hline 5 & 3253 & 24109 & 31021 & 35737 & 31810 & 35524 & & & & \\
\hline 6 & 28327 & 45709 & 55981 & 57516 & 61853 & & & & & \\
\hline 7 & 47351 & 72792 & 101345 & 102283 & & & & & & \\
\hline 8 & 47522 & 126588 & 173384 & & & & & & & \\
\hline 9 & 49025 & 136109 & & & & & & & & \\
\hline 10 & 43080 & & & & & & & & & \\
\hline
\end{tabular}

First, the weighted averages of the development factors in the cumulative paid claims were calculated by applying equation (3). The calculations of the parameter estimates $\hat{f}_{\mathrm{k}}$ for $1 \leq k \leq 9$ are displayed in Table 2.

Table 2. Weighted averages of development factors in the cumulative paid claims

\begin{tabular}{rrrrrrrrrr}
\hline$\hat{f}_{\mathrm{k}}$ & $\hat{\mathrm{f}}_{1}$ & $\hat{\mathrm{f}}_{2}$ & $\hat{\mathrm{f}}_{3}$ & $\hat{\mathrm{f}}_{4}$ & $\hat{\mathrm{f}}_{5}$ & $\hat{\mathrm{f}}_{6}$ & $\hat{\mathrm{f}}_{7}$ & $\hat{\mathrm{f}}_{8}$ & $\hat{\mathrm{f}}_{9}$ \\
\hline & 2.57 & 1.357 & 1.057 & 1.012 & 1.043 & 1.039 & 1.009 & 1.004 & 1.012 \\
\hline
\end{tabular}

Then, the future claims amounts were calculated by applying equation (4). Table 3 shows the future claims amounts.

Table 3. Future Claims Amounts (in EGP 1000)

\begin{tabular}{|c|c|c|c|c|c|c|c|c|c|c|}
\hline$i$ & $C_{i, 1}$ & $C_{i, 2}$ & $C_{i, 3}$ & $C_{i, 4}$ & $C_{i, 5}$ & $C_{i, 6}$ & $C_{i, 7}$ & $C_{i, 8}$ & $C_{i, 9}$ & $C_{i, 10}$ \\
\hline 2009 & 3260 & 24677 & 36412 & 40566 & 40582 & 40364 & 43536 & 43597 & 43808 & 44331 \\
\hline 2010 & 10096 & 32158 & 40485 & 42053 & 42582 & 42702 & 44880 & 45998 & 46133 & 46684 \\
\hline 2011 & 6635 & 27416 & 38242 & 41877 & 43138 & 42998 & 44229 & 44287 & 44458 & 44989 \\
\hline 2012 & 5359 & 26877 & 39252 & 42101 & 43014 & 48127 & 48409 & 48860 & 49049 & 49635 \\
\hline 2013 & 3253 & 24109 & 31021 & 35737 & 31810 & 35524 & 36924 & 37268 & 37412 & 37859 \\
\hline 2014 & 28327 & 45709 & 55981 & 57516 & 61853 & 64494 & 67035 & 67661 & 67922 & 68733 \\
\hline 2015 & 47351 & 72792 & 101345 & 102283 & 103515 & 107935 & 112188 & 113234 & 113671 & 115028 \\
\hline 2016 & 47522 & 126588 & 173384 & 183196 & 185401 & 193319 & 200936 & 202809 & 203593 & 206023 \\
\hline 2017 & 49025 & 136109 & 184707 & 195159 & 197509 & 205944 & 214058 & 216054 & 216888 & 219478 \\
\hline 2018 & 43080 & 110781 & 150336 & 158843 & 160756 & 167621 & 174225 & 175850 & 176529 & 178637 \\
\hline
\end{tabular}

The reserves for each accident year can be estimated by using equation (5). Table (4) summarizes estimated values of reserves until 6/30/2018.

Table 4. Estimates of claims reserves (in EGP 1000)

\begin{tabular}{cccc}
\hline $\begin{array}{c}\text { Accident Year }(i) \\
(1)\end{array}$ & $\begin{array}{c}\text { Estimated Ultimate Claims } \\
(2)\end{array}$ & $\begin{array}{c}\text { Cumulative Paid Claims at 6/30/2018 } \\
(3)\end{array}$ & $\begin{array}{c}\text { Estimated Reserves } \widehat{\boldsymbol{R}}_{\boldsymbol{i}} \\
(4)=(2)-(3)\end{array}$ \\
\hline 1 & 44331 & 44331 & $\mathbf{0}$ \\
2 & 46684 & 46133 & 551 \\
3 & 44989 & 44287 & 702 \\
4 & 49635 & 48409 & 1226 \\
5 & 37859 & 35524 & 2335 \\
6 & 68733 & 61853 & 6880 \\
7 & 115028 & 102283 & 12745 \\
8 & 206023 & 173384 & 32639 \\
9 & 219478 & 136109 & 83369 \\
10 & 178637 & 43080 & 135557 \\
\hline
\end{tabular}


Then the variance of paid claims in accident year $i$ and development year $k$ is estimated by applying equation (9). The calculations of the parameter estimates $\hat{\sigma}_{k}^{2}$ for $1 \leq k \leq 9$ are displayed in Table 5:

Table 5. Estimates of claims variance $\widehat{\sigma}_{\mathrm{k}}^{2}$

\begin{tabular}{|c|c|c|c|c|c|c|c|c|c|}
\hline & $k=1$ & $k=2$ & $k=3$ & $k=4$ & $k=5$ & $k=6$ & $k=7$ & $k=8$ & $k=9$ \\
\hline$\hat{\sigma}_{k}^{2}$ & 36087.623 & 287.509 & 126.198 & 157.062 & 169.149 & 42.295 & 8.245 & 0.083 & 0.001 \\
\hline
\end{tabular}

Then the variance of the estimated development factors $\widehat{\operatorname{Var}}\left(\hat{f}_{\mathrm{k}}\right)$ is calculated by using equation (17). Table 6 summarizes these values:

Table 6. Variance of the estimated development factors

\begin{tabular}{cc}
\hline$k$ & $\hat{\sigma}_{f_{k}}^{2}=\widehat{\operatorname{Var}}\left(\hat{\mathrm{f}}_{k}\right)$ \\
\hline 1 & 0.17969418 \\
3 & 0.00075595 \\
4 & 0.00036820 \\
5 & 0.00060443 \\
6 & 0.00084101 \\
7 & 0.00024281 \\
8 & 0.00006216 \\
9 & 0.00000093 \\
\hline
\end{tabular}

\subsection{Process Risk Estimation}

The process risk is estimated by using equation (8). Process risk estimates for future claims are calculated in a recursive manner from left to right, provided that the variance of the sum is the sum of the variances because of the independence of the accident years, $i=1 \ldots \ldots .10$.

It is noticed that equation (8) is divided into two parts: the first (upper) part, that is, in the case of $k>I+2-i$, and the second (lower) part, that is, in the case of $k=I+2-i$. The first value of each row is calculated from left to right by using the second part of equation (8), where $k=I+2-i$ (and always starts from left to right when estimating the process risk in the case of $\mathrm{k}=\mathrm{I}+2-\mathrm{i}$ for each row), and this value represents the basis on which we depend to calculate the rest of the process risk values in each row of the lower part calculated from the table of estimated future claims development through the first part of equation (8).

From here, the recursive method is applied to Murphy, and it is noticed that after completing the second row: $i=$ 2 , the process risk is estimated for the third row: $i=3$, starting from left to right and starting with $k=I+2-$ $i$, and so on until the tenth row: $i=10$, is completed. This can be also more or better explained through the following example:

In the case of the second row, start with the case $k=I+2-i$ where, $i=2$ and $k=10$, then:

Process $R_{l s k_{i, k}}=C_{i, I+1-i} \hat{\sigma}_{k-1}^{2}$

Process $R_{\imath s} k_{2,10}=C_{2,9} \hat{\sigma}_{9}^{2}=46133 * 0.001=46133=4.61 \mathrm{E}+01$

In the case of the third row, where $i=3$, the process risk is as follows:

- In the case of $k=9$ :

$$
\text { Process } \text { Risk }_{3,9}=C_{3,8} \hat{\sigma}_{8}^{2}=44287 * 0.083=3672.59=3.67 \mathrm{E}+03
$$

- In the case of $k=10$ :

$$
\begin{aligned}
\text { Process } \text { Rlsk }_{3,10} & =\hat{f}_{9}^{2} \text { Process R }_{\text {esk }}, 9+\hat{C}_{3,9} \hat{\sigma}_{9}^{2} \\
& =1.024 * 3.67 \mathrm{E}+03+44458 * 0.001 \\
& =3805.26=3.81 \mathrm{E}+03
\end{aligned}
$$

In the same way, the remaining accident years are estimated from $i=4$ to $i=10$.

Table 7 summarizes the values of the process risk estimates according to the accident year $i$ and the development year $k$ : 
Table 7. Estimates of the process risk values

\begin{tabular}{|c|c|c|c|c|c|c|c|c|c|c|}
\hline $\mathrm{i} / \mathrm{k}$ & $\mathrm{k}=1$ & $\mathrm{k}=2$ & $\mathrm{k}=3$ & $\mathrm{k}=4$ & $\mathrm{k}=5$ & $\mathrm{k}=6$ & $\mathrm{k}=7$ & $\mathrm{k}=8$ & $\mathrm{k}=9$ & $\mathrm{k}=10$ \\
\hline \multicolumn{11}{|l|}{$\mathrm{i}=1$} \\
\hline $\mathrm{i}=2$ & & & & & & & & & & $4.61 \mathrm{E}+01$ \\
\hline$i=3$ & & & & & & & & & $3.67 \mathrm{E}+03$ & $3.81 \mathrm{E}+03$ \\
\hline$i=4$ & & & & & & & & $3.99 \mathrm{E}+05$ & $4.06 \mathrm{E}+05$ & $4.16 \mathrm{E}+05$ \\
\hline$i=5$ & & & & & & & $1.50 \mathrm{E}+06$ & $1.84 \mathrm{E}+06$ & $1.85 \mathrm{E}+06$ & $1.90 \mathrm{E}+06$ \\
\hline$i=6$ & & & & & & $1.05 \mathrm{E}+07$ & $1.40 \mathrm{E}+07$ & $1.48 \mathrm{E}+07$ & $1.50 \mathrm{E}+07$ & $1.53 \mathrm{E}+07$ \\
\hline$i=7$ & & & & & $1.61 \mathrm{E}+07$ & $3.50 \mathrm{E}+07$ & $4.24 \mathrm{E}+07$ & $4.41 \mathrm{E}+07$ & $4.44 \mathrm{E}+07$ & $4.55 \mathrm{E}+07$ \\
\hline$i=8$ & & & & $2.19 \mathrm{E}+07$ & $5.12 \mathrm{E}+07$ & $8.70 \mathrm{E}+07$ & $1.02 \mathrm{E}+08$ & $1.06 \mathrm{E}+08$ & $1.07 \mathrm{E}+08$ & $1.09 \mathrm{E}+08$ \\
\hline$i=9$ & & & $3.91 \mathrm{E}+07$ & $6.70 \mathrm{E}+07$ & $9.93 \mathrm{E}+07$ & $1.41 \mathrm{E}+08$ & $1.61 \mathrm{E}+08$ & $1.66 \mathrm{E}+08$ & $1.68 \mathrm{E}+08$ & $1.72 \mathrm{E}+08$ \\
\hline$i=10$ & & $1.55 \mathrm{E}+09$ & $2.89 \mathrm{E}+09$ & $3.25 \mathrm{E}+09$ & $3.56 \mathrm{E}+09$ & $3.90 \mathrm{E}+09$ & $4.22 \mathrm{E}+09$ & $4.30 \mathrm{E}+09$ & $4.33 \mathrm{E}+09$ & $4.43 \mathrm{E}+09$ \\
\hline
\end{tabular}

\subsection{Parameter Risk Estimation}

By using equation (15), the parameter risk estimates for future claims are also calculated in a recursive manner from left to right. The parameter risk can be estimated in the same way as the process risk.

Table 8 summarizes the values of the parameter risk estimates according to the accident year $i$ and the development year $k$ :

Table 8. Estimates of the parameter risk values

\begin{tabular}{|c|c|c|c|c|c|c|c|c|c|c|}
\hline $\mathrm{i} / \mathrm{k}$ & $\mathrm{k}=1$ & $\mathrm{k}=2$ & $\mathrm{k}=3$ & $\mathrm{k}=4$ & $\mathrm{k}=5$ & $\mathrm{k}=6$ & $\mathrm{k}=7$ & $\mathrm{k}=8$ & $\mathrm{k}=9$ & $\mathrm{k}=10$ \\
\hline \multicolumn{11}{|l|}{$i=1$} \\
\hline$i=2$ & & & & & & & & & & $4.86 \mathrm{E}+01$ \\
\hline$i=3$ & & & & & & & & & $1.82 \mathrm{E}+03$ & $1.90 \mathrm{E}+03$ \\
\hline$i=4$ & & & & & & & & $1.46 \mathrm{E}+05$ & $1.49 \mathrm{E}+05$ & $1.53 \mathrm{E}+05$ \\
\hline$i=5$ & & & & & & & $5.62 \mathrm{E}+05$ & $6.58 \mathrm{E}+05$ & $6.64 \mathrm{E}+05$ & $6.80 \mathrm{E}+05$ \\
\hline$i=6$ & & & & & & $3.22 \mathrm{E}+06$ & $4.49 \mathrm{E}+06$ & $4.85 \mathrm{E}+06$ & $4.89 \mathrm{E}+06$ & $5.01 \mathrm{E}+06$ \\
\hline$i=7$ & & & & & $6.32 \mathrm{E}+06$ & $1.59 \mathrm{E}+07$ & $2.00 \mathrm{E}+07$ & $2.12 \mathrm{E}+07$ & $2.13 \mathrm{E}+07$ & $2.18 \mathrm{E}+07$ \\
\hline$i=8$ & & & & $1.11 \mathrm{E}+07$ & $3.16 \mathrm{E}+07$ & $6.33 \mathrm{E}+07$ & $7.75 \mathrm{E}+07$ & $8.15 \mathrm{E}+07$ & $8.21 \mathrm{E}+07$ & $8.41 \mathrm{E}+07$ \\
\hline $\mathrm{i}=9$ & & & $1.40 \mathrm{E}+07$ & $2.82 \mathrm{E}+07$ & $5.19 \mathrm{E}+07$ & $5.65 \mathrm{E}+07$ & $7.13 \mathrm{E}+07$ & $7.55 \mathrm{E}+07$ & $7.62 \mathrm{E}+07$ & $7.80 \mathrm{E}+07$ \\
\hline$i=10$ & & $3.33 \mathrm{E}+08$ & $6.24 \mathrm{E}+08$ & $7.05 \mathrm{E}+08$ & $7.38 \mathrm{E}+08$ & $8.24 \mathrm{E}+08$ & $8.98 \mathrm{E}+08$ & $9.16 \mathrm{E}+08$ & $9.23 \mathrm{E}+08$ & $9.46 \mathrm{E}+08$ \\
\hline
\end{tabular}

\subsection{Estimation of Process Risk, Parameter Risk and Total Standard Error for Each Accident Year i (Risk Estimates of Reserves)}

Process risk and parameter risk in the accident year $i$ are estimated by calculating the square root of the values of column $k=10$ (development year 10), as in Table 7 for the process risk and in Table 8 for the parameter risk, and the sum of the process risk column, which represents the overall process risk in the chain ladder method, is estimated by the square root of the sum of the squares of the values for this column, and the sum of the parameter risk column, which represents the overall parameter risk in the chain ladder method. In the same way, the total process risk and the total parameter risk, which together represent the total standard error of the reserves according to the chain ladder method, are also estimated through the square root of the sum of the squares of both values of the total process risk and the total parameter risk.

Table 9 shows Reserve Risk Estimates (process risk, parameter risk, and total standard error according to the accident year):

Table 9. Risk estimates for reserves

\begin{tabular}{cccc}
\hline$i$ & Process & Parameter & Total \\
\hline 2 & 7 & 7 & 10 \\
3 & 62 & 44 & 76 \\
4 & 645 & 391 & 754 \\
5 & 1377 & 825 & 1605 \\
6 & 3915 & 2238 & 4510 \\
7 & 6744 & 4674 & 8206 \\
8 & 10447 & 9171 & 13902 \\
9 & 13097 & 8831 & 15796 \\
10 & 66595 & 30750 & 73352 \\
Total & 69128 & 33695 & 76903 \\
\hline
\end{tabular}


It is noted that the value 76903 (in million Egyptian pounds) is the total standard error of reserves according to the chain ladder method for all accident years, which was calculated as follows:

$\sqrt{69128^{2}+33695^{2}}=76903$

Hence, the standard error percentage in the total claims reserves is as follows:

$$
\begin{aligned}
\% \text { s.e }(\hat{R}) & =\frac{\text { s.e }(\widehat{R})}{\widehat{R}} * 100 \\
\therefore \% \text { s.e }(\hat{R}) & =\frac{76903}{276003} * 100=27.9 \% \simeq 28 \%
\end{aligned}
$$

Murphy's goal was to provide a flexible and easy method for estimating both process risk and parameter risk, and at the same time trying to arrive at the same or the nearest estimates to Mack's model.

It can be seen that the recursive equations according to the Murphy model are not very concise albeit they are flexible as they allow estimation based on the transition in the model from a development year to the next development year by relying on the estimates of the previous year directly.

\section{Conclusions}

The chain ladder method is one of the most traditional deterministic methods used locally in Egyptian insurance companies and internationally. Deterministic methods of estimating claims reserves give a point estimate, which is likely to be wrong or correct.

The estimate of the total claims reserves which was estimated according to the deterministic chain ladder method is equal to 276003 million Egyptian pounds, which is a one-point estimate. And it is also noted that this estimate is the same as the total claims reserves which were estimated according to the stochastic Murphy model, except that it was noted that Murphy's model gave more information about the uncertainty of these estimates through estimating the process risk and parameter risk for each accident year and estimating the total standard error of the reserve.

The standard error in total claims reserve was estimated according to the Murphy model 28\% of the reserve, and this error includes both process risk and parameter risk.

From the above, the standard error expresses the accuracy of the estimator by measuring the spread of the values of the estimator around the parameter value, and thus the greater this spread, the greater the standard error of the estimator. Whereas the value of the estimated reserves is equal to 276003 and the ratio of the standard error of the estimator was $28 \%$ and therefore, the values of the estimator will be different from the parameter within the range of $28 \%$ by increase or decrease, and therefore, it can be said that the true reserves will be within the range of 28\%, increase or decrease from the estimated reserves, which is EGP 276003.

The reserve risk under the Mack's model was measured aggregately by the mean square error. Whereas in the Murphy model, both process risk and parameter risk were estimated separately.

The reserve risk equations according to Mack were brief and abbreviated, while the recursive equations according to Murphy's model were not very brief, but they were flexible, as they allow estimation based on the transition in the model from one development year to the next development year by depending on estimates of the immediately preceding year.

The deterministic claims reserving methods do not usually take into account some of the key factors that must be included in the estimation of these reserves.

The application of stochastic models for estimating claims reserves give quite satisfactory results and provide important details, so that it can become a better alternative and complementary to deterministic methods.

\section{References}

Ashe, F. (1986). An essay at measuring the variance of estimates of outstanding claim payments. ASTIN Bulletin: The Journal of the IAA, 16(S1), S99-S113. https://doi.org/10.1017/S0515036100011685

Björkwall, S. (2011). Stochastic claims reserving in non-life insurance: Bootstrap and smoothing models (Doctoral dissertation, Department of Mathematics, Stockholm University). Retrieved from https://www.diva-portal.org/

Charles, J., \& Westphal, S. (2006, April). Stochastic reserving. In CAE Spring Meeting. Retrieved from https://www.casact.org/

England, P. D., \& Verrall, R. J. (2001). A flexible framework for stochastic claims reserving. In Proceedings of the Casualty Actuarial Society (Vol. 88, No. 1, pp. 1-38). Retrieved from https://www.casact.org/ 
England, P. D., \& Verrall, R. J. (2002). Stochastic claims reserving in general insurance. British Actuarial Journal, 443-544. https://doi.org/10.1017/S1357321700003809

Gallagher, M. (2016). Workers Compensation Loss Projections. Retrieved from https://www.insurancepartnersacademy.com/wp-content/uploads/2011/09/2016-Work-Comp-Loss-Projectio ns-Collateral-Determination-1-16.pdf

Gutterman, S. (2017). IAA Risk Book Chapter 17-Risk and Uncertainty. Retrieved from https://www.actuaires.org/

Hayne, R. (2017). Basic Reserving Workshop. Casualty Actuarial Society (CAS). Retrieved from https://www.actuaries.org/

IOA, A. C. M. F., \& FIAA, G. M. P. (2016). A Practitioner's Introduction to Stochastic Reserving. Retrieved from https://www.actuaries.org.uk/

Lowe, J. (1994, September). A practical guide to measuring reserve variability using: Bootstrapping, operational time and a distribution free approach. In Proceedings of the 1994 General Insurance Convention. Institute of Actuaries and Faculty of Actuaries. Retrieved from https://www.actuaries.org.uk/

Mack, T. (1993). Distribution-free calculation of the standard error of chain ladder reserve estimates. ASTIN Bulletin: The Journal of the IAA, 23(2), 213-225. https://doi.org/10.2143/ast.23.2.2005092

Mack, T. (1999). The standard error of chain ladder reserve estimates: Recursive calculation and inclusion of a tail factor. ASTIN Bulletin: The Journal of the IAA, 29(2), 361-366. https://doi.org/10.2143/ast.29.2.504622

Mack, T., \& Venter, G. (2000). A comparison of stochastic models that reproduce chain ladder reserve estimates. Insurance: Mathematics and Economics, 26(1), 101-107. https://doi.org/10.1016/s0167-6687(99)00039-6

Majmudar, P. I., \& Parikh, N. K. (n. d.). Uncertainty in General Insurance and Solvency Issues. 10th Global Conference of Actuaries. Retrieved from https://www.actuariesindia.org/

Mann, E. M. (2011). A comparison of stochastic claim reserving methods. Retrieved from https://krex.k-state.edu/

Murphy, D. M. (2007). Chain ladder reserve risk estimators. In CAS E-Forum Summer. Retrieved from https://www.semanticscholar.org/

Ochola, E. O. (2009). A Stochastic Analysis of Claim Reserving in General Insurance Using Bootstrapping Technique. Diss. University of Nairobi. Retrieved from http://erepository.uonbi.ac.ke/

Ogutu, J. A. (2011). Claims reserving using overdispersed poisson model (Doctoral dissertation). Retrieved from http://erepository.uonbi.ac.ke/

Panning, W. H. (2006). Measuring loss reserve uncertainty. In Casualty Actuarial Society Forum (pp. 237-267). Retrieved from https://www.casact.org/

Pinheiro, P. J., Andrade e Silva, J. M., \& Lourdes Centeno, M. (2003). Bootstrap methodology in claim reserving. Journal of Risk and Insurance, 70(4), 701-714. https://doi.org/10.1046/j.0022-4367.2003.00071.x

Saluz, A. (2014). Stochastic Loss Reserving with Emphasis on the Bornhuetter-Ferguson Method. https://doi.org/10.3929/ethz-a-010358837

Straub, E., \& Grubbs, D. (1998). The Faculty and Institute of Actuaries Claims Reserving Manual. ASTIN Bulletin, 28(2). https://doi.org/10.1017/S0515036100012472

Tee, L., Käärik, M., \& Viin, R. (2017). On comparison of stochastic reserving methods with bootstrapping. Risks, 5(1), 2. https://doi.org/10.3390/risks5010002

Wüthrich, M. V., \& Merz, M. (2008). Stochastic claims reserving methods in insurance (Vol. 435). John Wiley \& Sons. Retrieved from tps://www.actuaries.ch

Wuthrich, M. V., \& Merz, M. (2015). Stochastic claims reserving manual: Advances in dynamic modeling. Swiss Finance Institute Research Paper, (15-34). https://doi.org/10.2139/ssrn.2649057

\section{Copyrights}

Copyright for this article is retained by the author(s), with first publication rights granted to the journal.

This is an open-access article distributed under the terms and conditions of the Creative Commons Attribution license (http://creativecommons.org/licenses/by/4.0/). 